BMJ Open

Sport \&

Exercise

Medicine

\title{
Fidelity, tolerability and safety of acute high-intensity interval training after hospitalisation for COVID-19: a randomised cross-over trial
}

Frederik Foged, ${ }^{1}$ Iben Elmerdahl Rasmussen, ${ }^{1}$ Josephine Bjørn Budde, ${ }^{1,2}$ Rasmus Syberg Rasmussen, ${ }^{1}$ Villads Rasmussen, ${ }^{1}$ Mark Lyngbæk, ${ }^{1}$ Simon Jønck, ${ }^{1}$ Rikke Krogh-Madsen, ${ }^{1,3,4}$ Birgitte Lindegaard, ${ }^{1,4,5}$ Mathias Ried-Larsen (D) , , Ronan Martin Griffin Berg (1) , 1,2,7,8 Regitse Højgaard Christensen ${ }^{1,9}$

To cite: Foged F, Rasmussen IE, Bjørn Budde J, et al. Fidelity, tolerability and safety of acute high-intensity interval training after hospitalisation for COVID-19: a randomised cross-over trial. BMJ Open Sport \& Exercise Medicine 2021;7:e001156. doi:10.1136/ bmjsem-2021-001156

- Additional supplemental material is published online only. To view, please visit the journal online (http://dx.doi. org/10.1136/bmjsem-2021001156).

FF and IER contributed equally.

Accepted 2 August 2021

Check for updates

(c) Author(s) (or their employer(s)) 2021. Re-use permitted under CC BY-NC. No commercial re-use. See rights and permissions. Published by BMJ.

For numbered affiliations see end of article.

\section{Correspondence to} Dr Ronan Martin Griffin Berg; ronan@sund.ku.dk

\section{ABSTRACT}

Objectives. Many patients with COVID-19 suffer from persistent symptoms, many of which may potentially be reversed by high-intensity interval training (HIIT). Yet, the safety and tolerability of HIIT after COVID-19 is controversial. This study aimed to investigate the fidelity, tolerability and safety of three different HIIT protocols in individuals that had recently been hospitalised due to COVID-19.

Methods. The study was a randomised cross-over trial. We compared three supervised HIIT protocols $(4 \times 4,6 \times 1$, 10-20-30) in 10 individuals recently discharged after hospitalisation for severe COVID-19. Each HIIT protocol had a duration of $38 \mathrm{~min}$ and was performed with a 1week washout between them. Outcomes included adverse events, exercise training intensity and tolerability assessed by the Likert scale $(1-10)$.

Results. All 10 participants aged 61 (mean, SD 8) years (5 males) completed all three HIIT protocols with no adverse events. High intensities were achieved in all three protocols, although they differed in terms of time spent with a heart rate $\geq 85 \%$ of maximum (mean (SD); $4 \times 4$ : 13.7 (6.4) min; 10-20-30: 12.1 (3.8) min; 6×1: 6.1 (5.6) $\min ; p=0.03)$. The three protocols were all well tolerated with similar Likert scale scores (mean (SD); $4 \times 4$ : 8 (2), 10-20-30: 8 (2), $6 \times 1: 9$ (2), $p=0.72$ ).

Conclusion. Our findings indicate that recently hospitalised individuals for severe COVID-19 may safely tolerate acute bouts of supervised HIIT as per protocol. This warrants future studies testing the potential of regular HIIT as a rehabilitation strategy in this context.

\section{INTRODUCTION}

It has become increasingly clear that a substantial proportion of patients suffering from COVID-19 develop so-called 'long COVID-19', that is, often invalidating symptoms including dyspnoea, chest pain, exercise intolerance and extreme fatigue, to mention a few, all of which persist way beyond the acute viral infection. ${ }^{1-4}$ The underlying

\section{Key messages}

What is already known

- Many patients suffering from COVID-19 develop socalled 'Iong COVID-19' which may be prevented or alleviated by targeted rehabilitation.

- High-intensity interval training (HIIT) is known to be a time-efficient rehabilitation intervention in several patient populations, notably in those with heart and lung disease.

\section{What are the new findings}

- Recently hospitalised patients who were mildly to slightly affected by long COVID-19 can satisfactorily complete acute exercise by the three most widely used HIIT protocols, so-called $4 \times 4,6 \times 1$ and $10-20$ 30 HIIT.

- Patients find HIIT both enjoyable and tolerable and we observed no adverse events.

- In patients recently hospitalised with COVID-19, the fidelity, tolerability and safety are comparable between the three HIIT protocols.

mechanisms of long COVID-19 are unknown but likely involve residual inflammation in the heart, lungs and vasculature. ${ }^{5}$ While the need for implementing evidence-based rehabilitation schemes that include exercise training following COVID-19 is imminent, no consensus exists as to how such programmes should be designed.

It is widely appreciated that high-intensity interval training (HIIT) promotes greater health-related benefits than traditional moderate-intensity training in various patient populations despite a reduced time commitment. $^{6-8}$ However, in the context of COVID-19 rehabilitation and long COVID-19 prevention, it has emerged as a particularly controversial training modality. Hence, several opinion papers and guidelines favour low-intensity exercise with gradual increases 
in intensity, mostly due to safety concerns. ${ }^{6-15}$ There is nonetheless currently no firm evidence base to argue in favour of this. A recent retrospective study on 28 discharged COVID-19 survivors conversely concluded that HIIT might safely be performed in these patients. ${ }^{16}$ Furthermore, in contrast to low-intensity and classical endurance exercise training, HIIT may more specifically target residual vascular inflammation, a putative central mechanism of long COVID-19. ${ }^{5}$ However, it is unknown to which extent it is feasible to implement HIIT in recently discharged patients with COVID-19, that is, whether they can tolerate HIIT without adverse effects.

In the present study, we assessed the fidelity, tolerability and safety of three widely used HIIT schemes in individuals recently discharged after hospitalisation for severe COVID-19.

\section{METHODS}

\section{Study design, participants and randomisation}

The study was performed from September to December 2020 at the Centre for Physical Activity Research at Rigshospitalet in Copenhagen, Denmark.

Ten recentlyk hospitalised individuals who had recovered from the acute phase of severe COVID-19 infection were included. Severe acute respiratory distress syndrome coronavirus 2 was confirmed by a PCR from a pharyngeal swap in all cases, and the COVID-19 was considered as severe when it had required hospitalisation with oxygen supplementation. Recovery from COVID-19 was defined as the time of hospital discharge. In terms of eligibility, the inclusion criteria were hospitalisation-requiring COVID19 , age $\geq 40$ years and $\leq 10$ L oxygen requirement during hospitalisation. Exclusion criteria were atrial fibrillation/ flutter, acute myocarditis, health conditions that prevent from participating in the exercise training intervention, and treatment with interleukin-6 receptor antagonists.

Participants underwent baseline testing, including a medical health interview and examination, arterial office blood pressure measurement, 12-lead ECG, a whole-body dual-energy X-ray absorptiometry, pulmonary function testing (dynamic spirometry, whole-body plethysmography and single-breath diffusing capacity to carbon monoxide). A maximal oxygen consumption $\left(\dot{\mathrm{V}}_{2 \max }\right)$ test was performed on a bicycle ergometer with a $5 \mathrm{~min}$ warm-up, immediately followed by a 15 Watt increase every minute until exhaustion. Participants completed a Post-COVID-19 Functional Status Scale (PFASS) questionnaire, ${ }^{17}$ which yields a score from 0 to 4 , where 0 indicates no functional limitations, 1 negligible functional limitations, 2 slight functional limitations, 3 moderate functional limitations and 4 severe functional limitations.

The participants were allocated to the random sequence by which order they would complete and evaluate the three HIIT protocols in a cross-over design as described below. Randomisation was performed by a researcher with no other role in the study who generated a block randomisation schedule with balanced permutations stratified by sex. The block sizes were not disclosed to ensure concealment, and participants were blinded for the sequence allocation until just before initiating the given HIIT session. To maintain blinding, the randomised sequence was delivered by email to a study investigator. The study investigator informed the participant before each training session which HIIT protocol to perform.

No changes in the trial design were made after the start of the experiments. It was not appropriate or possible to involve patients or the public in designing, conducting, reporting or disseminating our research. The original data that support the findings of this contribution can be obtained from the corresponding author on reasonable request.

\section{Exercise training interventions}

The three different HIIT protocols, including the specific training designs, are detailed in table 1 . The duration of the three HIIT protocols was matched in exercise duration (38 $\mathrm{min})$. A $10 \mathrm{~min}$ warm-up was followed by a block of interval exercises, with a duration between 21 and 25 min depending on the specific protocol, aiming at reaching a specific percentage of maximal heart rate $\left(\mathrm{HR}_{\max }\right)$ for $4 \times 4$, maximal workload (Watt ${ }_{\max }$ ) for $6 \times 1$ or subjective effort for 10-20-30 (further details in table 1). This was followed by a variable cool-down period (3-7 min) depending on the protocol. All exercise sessions were supervised by educated personnel.

\section{Fidelity and tolerability}

Fidelity was assessed by participant adherence to the prescribed training (dose reduction or dose modification) and the achieved intensity (table 1). The latter was evaluated by rate of perceived exertion (RPE) after each interval (6-20 Borg scale $)^{18}$ and after completed training (1-10 Borg scale), ${ }^{19}$ as well as from minutes above $85 \%$ of $\mathrm{HR}_{\text {max }}$. Furthermore, enjoyment and perceived tolerance were evaluated by the 10-point Likert scale. ${ }^{20}$

The primary qualitative evaluation of the HIIT protocols was an a priori defined composite endpoint based on three parameters: (1) participant adherence (fidelity), (2) a 10-point Likert scale (tolerability) and (3) adverse events (safety). This was displayed by a red-amber-green system inspired by a previous publication ${ }^{21}$ (table 2 ). The lowest of the three parameters determined the overall red-amber-green rank of the given HIIT protocol in the individual participant. No changes in outcomes were made after the start of the experiments.

\section{Safety}

At the baseline visit, all participants underwent a medical health interview and examination to assess health status. The following contraindications and precautions were considered: acute or recurring chest pain or systolic blood pressure $>200 \mathrm{~mm} \mathrm{Hg} \pm$ diastolic blood pressure $>100$ $\mathrm{mmHg}$. Safety during exercise training was assessed as the following, which also served as termination criteria: 
Table 1 Structure of the three different high-intensity interval training protocols

\begin{tabular}{|c|c|c|c|}
\hline & $4 \times 4$ & $6 \times 1$ & $10-20-30$ \\
\hline Total time & $38 \mathrm{~min}$ & $38 \min$ & $38 \mathrm{~min}$ \\
\hline Warm-up & $\begin{array}{l}10 \text { min warm-up with a heart rate of } \\
60 \%-70 \% \text { of } \mathrm{HR}_{\max }\end{array}$ & 10 min warm-up on $30 \%$ of Watt max & $\begin{array}{l}10 \text { min warm-up at } 60 \%-70 \% \text { of } \\
H R_{\max }\end{array}$ \\
\hline Intervals & $\begin{array}{l}\text { Four intervals of } 4 \text { min at an intensity } \\
\text { that will induce at least } 85 \% \text { of } \mathrm{HR}_{\max } \\
\text { (starting at } 75 \% \text { of Watt }{ }_{\text {max }} \text { ). } \\
\text { Each interval is separated by } 3 \text { min } \\
\text { active pauses, biking at } 50 \%-70 \% \\
\text { of } \mathrm{HR}_{\max }\end{array}$ & $\begin{array}{l}\text { Six intervals of } 1 \text { min at } 100 \% \text { of the } \\
\text { Watt } \\
\text { Eax } \\
\text { Each interval is interspersed by } 3 \text { min } \\
\text { active pauses at } 30 \% \text { of Watt }{ }_{\text {max }}\end{array}$ & $\begin{array}{l}\text { Three intervals of } 5 \text { min interspersed } \\
\text { by } 3 \text { min at } 50 \%-70 \% \text { of HR } \\
\text { Each interval set consists of } 5 \text { min } \\
\text { of five repeated } 30-20-10 \text { intervals, } \\
\text { consisting of } 30 \mathrm{~s} \text { at easy pace, } 20 \mathrm{~s} \\
\text { at medium pace and } 10 \mathrm{~s} \text { at all-out. }\end{array}$ \\
\hline Cool-down & $\begin{array}{l}3 \text { min cool-down at } \sim \text { warm up } \\
\text { intensity }\end{array}$ & $\begin{array}{l}7 \text { min cool-down at } \sim \text { warm-up } \\
\text { intensity }\end{array}$ & $\begin{array}{l}7 \text { min cool-down at } \sim \text { warm-up } \\
\text { intensity }\end{array}$ \\
\hline Success criteria & $\begin{array}{l}\text { The participant must spend at least } \\
25 \% \text { of the interval above } 85 \% \text { of } \\
\mathrm{HR}_{\text {max }} \text {. } \\
\text { The participant needs to reach } 85 \% \\
\text { of } \mathrm{HR}_{\text {max }} \text { during the first } 3 \text { min of } \\
\text { each } 4 \text { min interval. If the participant } \\
\text { does not reach } 85 \% \text { of } \mathrm{HR}_{\text {max }} \text {, the } \\
\text { last minute of the } 4 \text { min interval, the } \\
\text { workload will be increased based } \\
\text { on how far the heart rate is from the } \\
\text { prescribed target. } \\
\text { Likewise, the workload will be } \\
\text { reduced if the RPM falls below } 60 \text { or } \\
\text { in the next interval if the HR exceeds } \\
95 \% \text { of } \mathrm{HR}_{\text {max }}\end{array}$ & $\begin{array}{l}\text { The participant must keep a pace } \\
\text { above } 60 \text { rounds per minute during } \\
\text { each interval. If the participant is not } \\
\text { capable of keeping the right pace, } \\
\text { the workload will be downgraded by } \\
10 \% \text { from the next interval. }\end{array}$ & $\begin{array}{l}\text { The participant must spend at least } \\
25 \% \text { of each interval above } 85 \% \text { of } \\
\mathrm{HR}_{\max }\end{array}$ \\
\hline
\end{tabular}

$\mathrm{HR}_{\text {max }}$, maximal heart rate; RPM, rounds per minute; Watt ${ }_{\max }$, maximal workload (in Watt).

onset of angina, signs of poor perfusion (confusion, nausea, lightheadedness, central cyanosis), requests to terminate (eg, due to intolerable dyspnoea), and physical or verbal manifestations of severe fatigue. A 12-lead ECG was obtained after each HIIT session to assess whether there was evidence of arrhythmia or myocardial ischaemia.

\section{Statistics}

The HIIT protocols were compared using analysis of covariance (ANCOVA) modelling for training intensity (minutes above $85 \%$ of $\mathrm{HR}_{\max }$ ), the Likert scale, RPE and PFASS. Unless otherwise stated, data are reported as mean (SD) or median (IQR). The sample size was

Table 2 Red-amber-green system designed to evaluate the three high-intensity interval training protocols

\begin{tabular}{|c|c|c|c|}
\hline & Red & Amber & Green \\
\hline Dose reduction & $\begin{array}{l}\text { If } \leq 50 \% \text { of the total training duration } \\
\text { is completed }\end{array}$ & $\begin{array}{l}\text { If } 50 \%-85 \% \text { of the training } \\
\text { duration is completed }\end{array}$ & $\begin{array}{l}\text { If } \geq 85 \% \text { of the training duration is } \\
\text { completed }\end{array}$ \\
\hline $\begin{array}{l}\text { Specific dose reduction for } \\
4 \times 4 \text { min }\end{array}$ & $\begin{array}{l}\text { If } \mathrm{HR} \text { has been above } 85 \% \text { of } \\
\text { max }<15 \% \text { of the time during the } \\
\text { intervals }(<2: 20)\end{array}$ & $\begin{array}{l}\text { If } \mathrm{HR} \text { has been above } 85 \% \\
\text { of max } 15 \%-24 \% \text { of the time } \\
\text { during intervals (2:20-3:50) }\end{array}$ & $\begin{array}{l}\text { If } \mathrm{HR} \text { has been above } 85 \% \text { of } \max \geq 25 \% \\
\text { of the time during intervals }(\geq 3: 50)\end{array}$ \\
\hline $\begin{array}{l}\text { Specific dose reduction for } \\
6 \times 1 \mathrm{~min}\end{array}$ & $\begin{array}{l}\text { If the intensity must be } \\
\text { downgraded } \geq 10 \% \text { in five or more of } \\
\text { the intervals }\end{array}$ & $\begin{array}{l}\text { If the intensity must be } \\
\text { downgraded } 10 \% \text { in } 3-4 \text { of } \\
\text { the intervals }\end{array}$ & $\begin{array}{l}\text { If the intensity must be downgraded } 10 \% \\
\text { in }<3 \text { of the intervals }\end{array}$ \\
\hline $\begin{array}{l}\text { Specific dose reduction for } \\
10-20-30\end{array}$ & $\begin{array}{l}\text { If } \mathrm{HR} \text { has been above } 85 \% \text { of } \\
\text { max }<15 \% \text { of the time during the } \\
\text { intervals }(<2: 15)\end{array}$ & $\begin{array}{l}\text { If } \mathrm{HR} \text { has been above } 85 \% \\
\text { of max } 15 \%-24 \% \text { of the time } \\
\text { during intervals ( } 2: 15-3: 40)\end{array}$ & $\begin{array}{l}\text { If } \mathrm{HR} \text { has been above } 85 \% \text { of } \max \geq 25 \% \\
\text { of the time during intervals }(\geq 3: 40)\end{array}$ \\
\hline $\begin{array}{l}\text { Likert scale } \\
\text { (tolerability) }\end{array}$ & $1-2$ & $3-4$ & $5+$ \\
\hline Adverse events & $\begin{array}{l}\text { If the participant experiences angina, } \\
\text { must stop the training due to any } \\
\text { adverse event or has ST depression } \\
\text { or arrhythmia on the post-training } \\
\text { ECG }\end{array}$ & $\begin{array}{l}\text { If } \geq 3 \text { adverse events are } \\
\text { registered during the training } \\
\text { session }\end{array}$ & $\begin{array}{l}\text { If } \leq 2 \text { adverse events are registered during } \\
\text { the training session }\end{array}$ \\
\hline
\end{tabular}

HR, heart rate . 


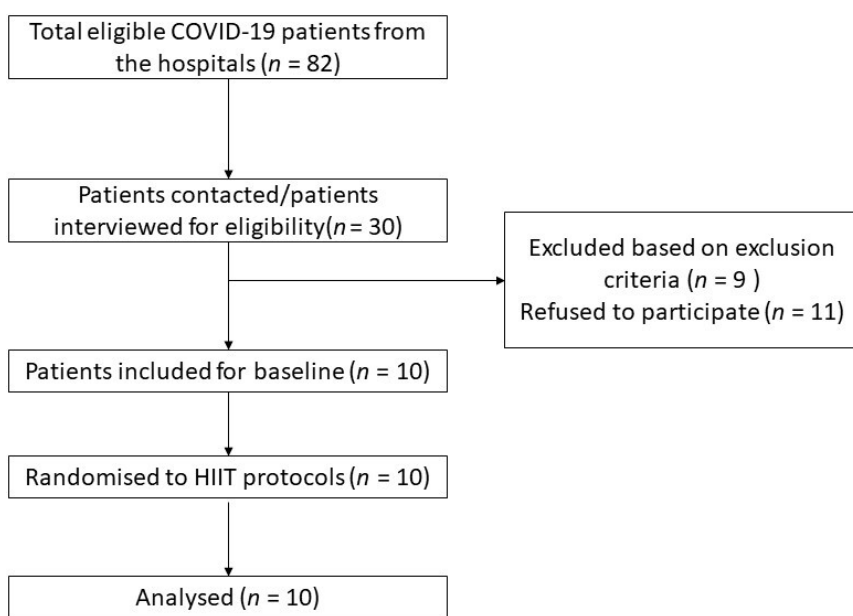

Figure 1 Study flow chart. Flow chart of participants included in the study.

determined on what was feasible within the local context under considerations of reducing the number of participants to exposure of potential harms. All analyses were performed using GraphPad Prism, V.7.02 (GraphPad Software) or STATA/SE (StataCorp) V.16.1, and a twotailed $\mathrm{p}<0.05$ was considered statistically significant.

\section{RESULTS}

The study flow diagram is shown in figure 1 . A total of 10 participants were enrolled and randomised and complied with the three HIIT protocols, and all participants were thus included in the analysis (attendance 100\%). Baseline characteristics, including lung function and PFASS scores, are presented in table 3. All participants except for one with a restrictive pattern had normal ventilatory capacity, while five had reduced diffusing capacity (mild reduction in three cases, moderate-to-severe in two cases). Generally, the participants were only mildly to slightly affected by persisting COVID-19 symptoms according to PFASS scores, with the highest score of 3 in one individual. The primary reason for not participating was feeling too weak to exercise after the infection.

Outcomes of the three HIIT training protocols were compared by a red-amber-green design (table 2). No 'red' training sessions occurred, and only $1 / 10$ training session in $4 \times 4$ was amber due to a low Likert score (tolerable: $3 / 10$ ), and $1 / 10$ in the $10-20-30$ was amber due to inadequate time spent $>85 \%$ of $\mathrm{HR}_{\max }$ as prescribed. The rest of the training sessions were reported as green, which means all three HIIT protocols are tolerable and safe (figure 2). No adverse events were reported during the study, and no angina or ECG changes were seen after HIIT training.

There was a between-protocol difference in terms of the exercise intensity when dichotomously assessing for time spent with a heart rate $\geq 85 \%$ of $\mathrm{HR}_{\text {max }}$ (figure $3 \mathrm{~A}$ ). In contrast, tolerability as assessed by Likert scale scores (figure 3B) and RPE (4×4; 5 (2), 6×1; 5 (2), 10-20-30; 6 (2); $\mathrm{p}=0.28$ ) did not differ between protocols. When considering HR and RPE changes non-dichotomously,
Table 3 Baseline characteristics

\begin{tabular}{|c|c|}
\hline $\begin{array}{l}\text { Measurement } \\
\text { (mean (SD) or median (IQR)) }\end{array}$ & \\
\hline Age (years) & $61(8)$ \\
\hline Height (cm) & $172(7)$ \\
\hline Weight (kg) & $78.3(10.8)$ \\
\hline Fat mass (\%) & $35.5(7.7)$ \\
\hline BMD (T-score) & $1.22(0.07)$ \\
\hline $\mathrm{FEV}_{1}(\%-$ pred $)$ & $110(19)$ \\
\hline FVC (\%-pred) & $112(16)$ \\
\hline $\mathrm{FEV}_{1} / \mathrm{FVC}$ & $81(10)$ \\
\hline RV (\%-pred) & $89(21)$ \\
\hline TLC (\%-pred) & $94(15)$ \\
\hline $\mathrm{D}_{\mathrm{L}} \mathrm{COc}(\%-$ pred $)$ & $78(20)$ \\
\hline $\mathrm{VO}_{2 \max }(\mathrm{mL} / \mathrm{min})$ & $1968(766)$ \\
\hline $\mathrm{VO}_{2 \max }(\mathrm{mL} / \mathrm{min} / \mathrm{kg})$ & $24.9(8.8)$ \\
\hline Duration of hospitalisation (days) & $7(4)$ \\
\hline Time since discharge (days) & $40(22-145)$ \\
\hline PFASS & $2(0-2)$ \\
\hline
\end{tabular}

Anthropometry measured at baseline.

$\mathrm{BMD}$, bone mass density; $\mathrm{D}_{\mathrm{L}} \mathrm{COc}$, carbon monoxide diffusing capacity corrected for haemoglobin; PFASS, Post-COVID-19 Functional Status Scale; RPE, rate of perceived exertion; RV, residual volume; TLC, total lung capacity; $\mathrm{VO}_{2 \max }$, maximal oxygen consumption.

largely similar objective and subjective measures of intensities were observed throughout each protocol (online supplemental figures 1 and 2).

\section{DISCUSSION}

This study compared the fidelity, tolerability and safety of three HIIT protocols conducted on individuals recently hospitalised with COVID-19. Our findings indicate that HIIT is feasible regarding fidelity, tolerability and safety, regardless of the specific protocol.

No adverse events occurred in any of the HIIT protocols. These results are in line with a previous study on COVID-19 survivors, ${ }^{16}$ as well as several studies on other 'high risk' patient groups such as ischaemic heart disease and heart failure in whom it is considered safe. ${ }^{622}$ Thus, we consider it unlikely that HIIT should be associated with a high risk of acute adverse cardiovascular events. This concern was raised in The Stanford Consensus Statement for Post-COVID-19 Rehabilitation as one of the primary arguments against HIIT use in these individuals. ${ }^{23}$ However, studies with regular exercise are needed to determine the long-term safety of HIIT in this context.

We found that while all three HIIT protocols were well tolerated, the greatest intensity, given by the time spent above $85 \%$ of $\mathrm{HR}_{\max }$, was achieved by $4 \times 4$. Time spent above $85 \%$ of $\mathrm{HR}_{\text {max }}^{\text {max }}$ was chosen since HIIT is widely defined as training intensities at $85 \%-90 \%$ of $\mathrm{HR}_{\max }{ }^{724}$ The cut-off, $85 \%$ of $\mathrm{HR}_{\max }$, is arbitrarily defined, and the 


\section{Red-amber-green}

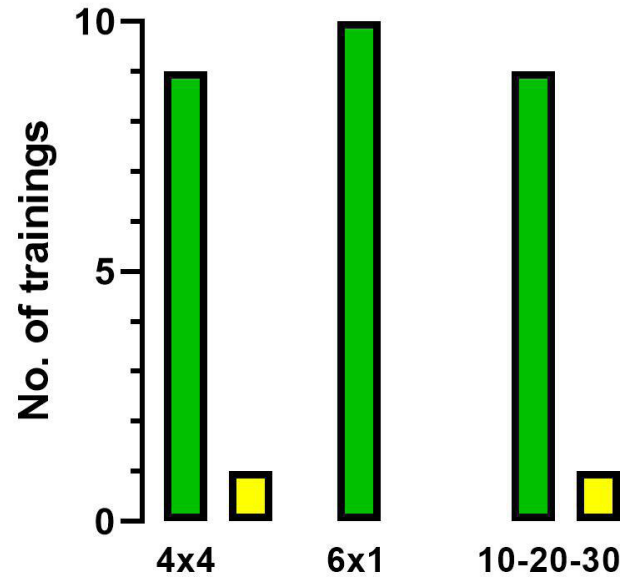

Figure 2 Red-amber-green. Number of 'red', 'amber' and 'green' training sessions of the three high-intensity interval training protocols.

supplemental graphic overview shows that all protocols performed well with high RPE and HR reaching maximum in all protocols. These findings, combined with the strong physiological rationale for HIIT, highlight it as an attractive option for COVID-19 rehabilitation. This is further invigorated when considering the widespread and disease-specific vascular inflammation in COVID-19 that persists after the acute viral infection and which is thought to contribute to the very diverse cluster of symptoms associated with long COVID-19. ${ }^{25}$ Potentially, this may be specifically counteracted with HIIT, where the pronounced changes in vascular shear stress that occur between intervals combined with the effects of antiinflammatory myokines that are released from working skeletal muscle in an intensity-dependent manner may enhance endothelial repair and dampen proinflammatory processes within the vascular wall.
A

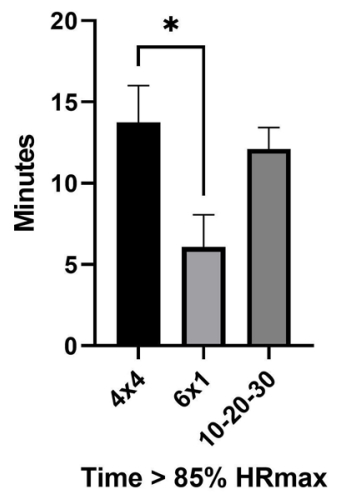

B

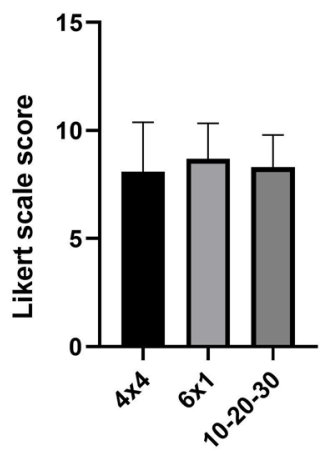

Tolerability
Figure 3 Intensity and tolerability. (A) Intensity: time spent with a heart rate $>85 \%$ of maximum for each protocol. (B) Tolerability rated by the Likert scale. Data are presented as mean $(95 \% \mathrm{Cl}) ;{ }^{*} \mathrm{p}=0.028$. $\mathrm{HR}_{\text {max }}$, maximal heart rate.
The high composite intensity achieved is the bestdocumented means for increasing maximal oxygen consumption $\left(\mathrm{V}^{2} \mathrm{O}_{\max }\right)$ and exerting beneficial cardiovascular effects. HIIT has thus been reported to be superior to continuous endurance training in several patient groups. ${ }^{76}$ These include patients with hypertension, ischaemic heart disease and heart failure, in which $\dot{\mathrm{VO}}_{2 \max }$ has furthermore been noted as the single best predictor of mortality. ${ }^{27} 28$ It remains to be determined whether this is also the case in various lung diseases, such as chronic obstructive pulmonary disease. Still, HIIT has been noted to be associated with higher adherence in these patients, conceivably because the intermittent nature of HIIT reduces ventilatory demand and thus exertional dyspnoea and perceived breathing effort. ${ }^{29} 30$ This may also apply to patients recovering from COVID19. Even though the present study is small scale in this context, and larger randomised controlled studies are warranted, we posit that HIIT should also be considered among the preferred training modalities in the rehabilitation post-COVID-19.

A strength of the study is the randomised sequence of the exercise training protocols, which eliminated systematic carry-over effects of the previous training protocol. Another strength is that this is the first study testing HIIT protocols post-COVID-19 in a supervised manner. Moreover, our research investigated the fidelity, tolerable and safety of three various HIIT protocols with different work or intensity periods, thus enabling between-protocol comparisons.

Some limitations should be considered when interpreting the results of this study. First, our results may be affected by selection bias because the main reason for declining participation was feeling too weak to exercise, which may indeed be a symptom of long COVID-19. Our results regarding fidelity and tolerability may thus have been different if we had studied these patients, which arguably represent the group that may benefit the most from targeted rehabilitation. Another important limitation is the small study size $(n=10)$ which limits the conclusions, particularly when considering the heterogeneity of the participants. Furthermore, we only tested the fidelity, tolerability and safety to acute HIIT and cannot draw any firm conclusions regarding training over extended periods. Even though we expect a HIITbased rehabilitation scheme over an extended period to be feasible, this remains speculative.

In conclusion, we found that individuals recently recovered from COVID-19 could successfully and safely complete three acute bouts of the most widely used HIIT protocols. Our findings highlight that HIIT should be evaluated as a rehabilitation strategy for post-COVID-19 in future randomised controlled trials.

\section{Author affiliations}

${ }^{1}$ Centre for Physical Activity Research, Rigshospitalet, Copenhagen, Denmark ${ }^{2}$ Department of Biomedical Sciences, Faculty of Health and Medical Sciences, University of Copenhagen, Copenhagen, Denmark 
${ }^{3}$ Department of Infectious Diseases, Hvidovre Hospital, Hvidovre, Denmark ${ }^{4}$ Department of Clinical Medicine, Faculty of Health and Medical Sciences, University of Copenhagen, Copenhagen, Denmark

${ }^{5}$ Department of Pulmonary Medicine and Infectious Diseases, Hillerød Hospital, Hillerød, Denmark

${ }^{6}$ Institute of Sports Science and Clinical Biomechanics, University of Southern Denmark Faculty of Health Sciences, Odense, Denmark

${ }^{7}$ Department of Clinical Physiology, Nuclear Medicine \& PET, Rigshospitalet, Copenhagen, Denmark

${ }^{8}$ Neurovascular Research Laboratory, Faculty of Life Sciences and Education, University of South Wales, Pontypridd, UK

${ }^{9}$ Department of Cardiology, Rigshospitalet, Copenhagen, Denmark

Twitter Ronan Martin Griffin Berg @cresp_research @ronan_berg @cfas_dk Contributors Conceptualisation: RHC, RMGB, MR-L. Methodology: RHC, RMGB, VR, MR-L, RKM, BLM. Formal analysis: FF, IER, RHC, RMGB, MR-L. Investigation, FF, IER, JBB, RSR, ML, SJ, RHC, RMGB, BLM, RKM. Supervision: RMGB, RHC. Resources: RMGB, RHC. Writing —original draft: FF, IER. Writing — review and editing: All authors contributed. Visualisation: FF, IER, MR-L.

Funding The Centre for Physical Activity Research (CFAS) is supported by a grant from TrygFonden, and the Centre of Inflammation and Metabolism (CIM) is a member of DD2-the Danish Center for Strategic Research in Type 2 Diabetes (the Danish Council for Strategic Research, grant nos. 09-067009 and 09-075724).

Competing interests None declared.

Patient and public involvement Patients and/or the public were not involved in the design, or conduct, or reporting or dissemination plans of this research.

Patient consent for publication Not required.

Ethics approval The study was conducted per the Declaration of Helsinki with oral and written informed consent from all participants before inclusion and approved by the Scientific Ethical Committee of the Capital Region of Denmark (H-20033733 including amendment 75068 and 75799) and the Danish Data Protection Agency (P-2020-781) and pre-registered at ClinicalTrials.gov (NCT04549337).

Provenance and peer review Not commissioned; externally peer reviewed.

Data availability statement Data are available on reasonable request. The original data that support the findings of this contribution can be obtained from the corresponding author on reasonable request.

Open access This is an open access article distributed in accordance with the Creative Commons Attribution Non Commercial (CC BY-NC 4.0) license, which permits others to distribute, remix, adapt, build upon this work non-commercially, and license their derivative works on different terms, provided the original work is properly cited, appropriate credit is given, any changes made indicated, and the use is non-commercial. See: http://creativecommons.org/licenses/by-nc/4.0/.

\section{ORCID iDs}

Mathias Ried-Larsen http://orcid.org/0000-0002-8388-5291

Ronan Martin Griffin Berg http://orcid.org/0000-0002-5757-9506

\section{REFERENCES}

1 Alwan NA, Attree E, Blair JM, et al. From doctors as patients: a manifesto for tackling persisting symptoms of covid-19. BMJ 2020;370:m3565.

2 Bos LDJ, Brodie D, Calfee CS. Severe COVID-19 InfectionsKnowledge gained and remaining questions. JAMA Intern Med 2021;181:9-11.

3 Rubin R. As Their Numbers Grow, COVID-19 "Long Haulers" Stump Experts. JAMA 2020;324:1381-5.

4 Carfi A, Bernabei R, Landi F, et al. Persistent symptoms in patients after acute COVID-19. JAMA 2020;324:603-5.

5 Christensen RH, Berg RMG. Vascular Inflammation as a Therapeutic Target in COVID-19 "Long Haulers": HIITing the Spot? Front Cardiovasc Med 2021;8:643626.

6 Batacan RB, Duncan MJ, Dalbo VJ, et al. Effects of high-intensity interval training on cardiometabolic health: a systematic review and meta-analysis of intervention studies. $\mathrm{Br} J$ Sports Med 2017:51:494-503.

7 Karlsen T, Aamot I-L, Haykowsky M, et al. High intensity interval training for maximizing health outcomes. Prog Cardiovasc Dis 2017;60:67-77.

8 Gillen JB, Gibala MJ. Is high-intensity interval training a time-efficient exercise strategy to improve health and fitness? Appl Physiol Nutr Metab 2014;39:409-12.

9 Leandro CG, Ferreira E Silva WT, Lima-Silva AE. Covid-19 and exercise-induced immunomodulation. Neuroimmunomodulation 2020;27:75-8.

10 Rahmati-Ahmadabad S. Exercise against SARS-CoV-2 (COVID-19): does workout intensity matter? Obes Med 2020;19:100245.

11 Bhatia RT, Marwaha S, Malhotra A, et al. Exercise in the Severe Acute Respiratory Syndrome Coronavirus-2 (SARS-CoV-2) era: A Question and Answer session with the experts Endorsed by the section of Sports Cardiology \& Exercise of the European Association of Preventive Cardiology (EAPC). Eur J Prev Cardiol 2020;27:1242-51.

12 Verwoert GC, de Vries ST, Bijsterveld N, et al. Return to sports after COVID-19: a position paper from the Dutch Sports Cardiology Section of the Netherlands Society of Cardiology. Neth Heart $J$ 2020;28:391-5.

13 Dores H, Cardim N. Return to play after COVID-19: a sport cardiologist's view. Br J Sports Med 2020;54:1132-3.

14 Denay KL, Breslow RG, Turner MN. ACSM call to action statement: COVID-19 considerations for sports and physical activity. $N$ Engl J Med 2020;383:120-8.

15 Kennedy FM, Sharma S. COVID-19, the heart and returning to physical exercise. Occup Med 2020;70:19-21.

16 Hermann M, Pekacka-Egli A-M, Witassek F, et al. Feasibility and efficacy of cardiopulmonary rehabilitation after COVID-19. Am J Phys Med Rehabil 2020;99:865-9.

17 Klok FA, Boon GJAM, Barco S, et al. The Post-COVID-19 functional status scale: a tool to measure functional status over time after COVID-19. Eur Respir J 2020;56:2001494.

18 Borg GAV. Psychophysical bases of perceived exertion. Plast Reconstr Surg 1954;14:377-81

19 Shariat A, Cleland JA, Danaee M, et al. Borg CR-10 scale as a new approach to monitoring office exercise training. Work 2018;60:549-54.

20 Afthanorhan A. The Likert scale analysis using parametric based structural equation modeling (SEM). Computational Methods in Social Sciences 2016;4:13-21.

21 Avery KNL, Williamson PR, Gamble C, et al. Informing efficient randomised controlled trials: exploration of challenges in developing progression criteria for internal pilot studies. BMJ Open 2017;7:e013537

22 Giallauria F, Piccioli L, Vitale G, et al. Exercise training in patients with chronic heart failure: a new challenge for cardiac rehabilitation community. Monaldi Arch Chest Dis 2018;88:38-44.

23 Barker-Davies RM, O'Sullivan O, Senaratne KPP, et al. The Stanford Hall consensus statement for post-COVID-19 rehabilitation. $\mathrm{Br} J$ Sports Med 2020;54:949-59.

24 Wisløff U, Ellingsen Øyvind, Kemi OJ. High-Intensity interval training to maximize cardiac benefits of exercise training? Exerc Sport Sci Rev 2009;37:139-46.

25 Sollini M, Ciccarelli M, Cecconi M, et al. Vasculitis changes in COVID-19 survivors with persistent symptoms: an $\left[{ }^{18} \mathrm{~F}\right] \mathrm{FDG}-\mathrm{PET} / \mathrm{CT}$ study. Eur J Nucl Med Mol Imaging 2021;48:1460-6.

26 Helgerud J, Høydal K, Wang E, et al. Aerobic high-intensity intervals improve VO2max more than moderate training. Med Sci Sports Exerc 2007:39:665-71.

27 Myers J, Prakash M, Froelicher V, et al. Exercise capacity and mortality among men referred for exercise testing. $N$ Engl $\mathrm{J}$ Med 2002;346:793-801.

28 Kavanagh T, Mertens DJ, Hamm LF, et al. Prediction of longterm prognosis in 12169 men referred for cardiac rehabilitation. Circulation 2002;106:666-71.

29 Sawyer A, Cavalheri V, Hill K. Effects of high intensity interval training on exercise capacity in people with chronic pulmonary conditions: a narrative review. BMC Sports Sci Med Rehabil 2020;12:22.

30 Kortianou EA, Nasis IG, Spetsioti ST, et al. Effectiveness of interval exercise training in patients with COPD. Cardiopulm Phys Ther $J$ 2010;21:12-19. 